$\mathrm{DOE} / \mathrm{ER} / 45419--2$

DE92 011751

\section{ROLE OF STRUCTURE IN ION MOVEMENT OF GLASSES}

\section{Progress Report}

for Period January 14, 1991 to January 15, 1992

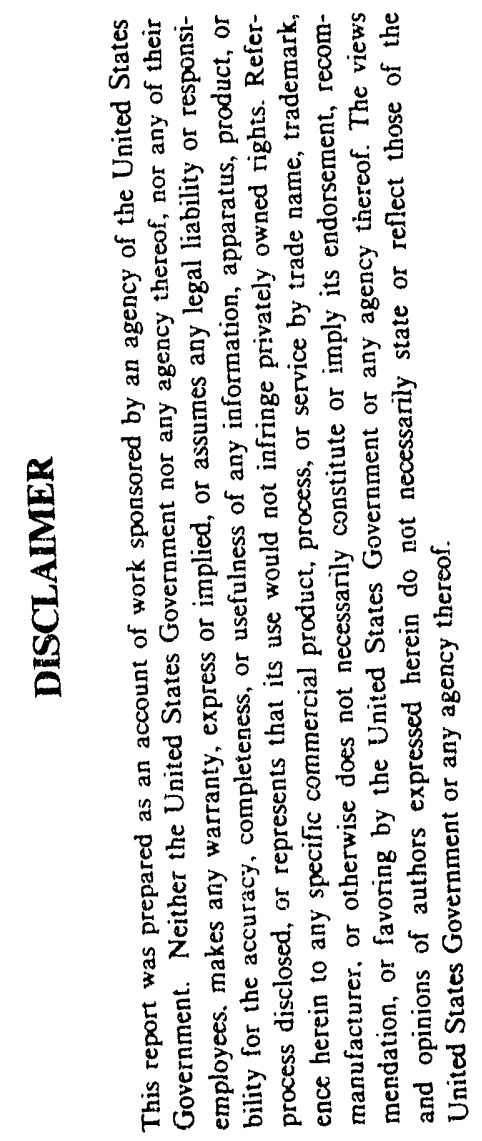

Himanshu Jain

Lehigh University

Bethlehem, Pennsylvania 18015

January 15, 1992

Prepared for

THE U. S. DEPARTMENT OF ENERGY

AGREEMENT NO. DE-FG02-90ER45419

MIISTER 


\title{
ROLE OF STRUCTURE IN ION MOVEMENT IN GLASSES
}

(Grant DE-FG02-90-ER45419)

\author{
Summary of Progress for the Period \\ January 16, 1991 - January 15, 1992
}

Can the structure of a melt much above the glass transition temperature ( $\mathrm{Tg}$ ) determine the structure and (transport) properties of glass? In other words, are there extremely long lasting configurations in a melt which would affect ion transport in the glassy state? A major effort during the past year has been to address these very fundamental questions. An important consideration here is to separate the effect of the variable melt structure from that of a variable cooling rate in the glass transformation range. For this reason our experiment consists of preparing $0.3 \mathrm{Na}_{2} \mathrm{O}-0.7 \mathrm{~B}_{2} \mathrm{O}_{3}$ glasses from the melt which is first equilibrated at $1400 \mathrm{C}$ and then annealed at $850 \mathrm{C}$ for 0 to 180 minutes. From $850 \mathrm{C}$ variously annealed melts are quenched to the glassy state by following identical procedure. If the structure (as reflected in ion transport) of $1400 \mathrm{C}$ melt relaxes to that of $850 \mathrm{C}$ in $\sim$ minutes, we may expect to observe variations in the conductivity time in the ns range.

Because the composition and cooling rate are the same for all samples, one expects rather small, if any, difference among the samples and high accuracy of the measurements is critical. To avoid errors from sample geometry measurements, we have chosen to compare the activation energy of conductivity $(E)$ of various samples. The results show $E$ to vary within $0.017 \mathrm{eV}$ which is more than the reproducibility limit of our measurements 
on glasses prepared from the same batch. Further, statistically from two sets of experiments E appears to decrease with increasing annealing time (t). Assuming that the melt at 1400 $\mathrm{C}$ has more open structure than at $850 \mathrm{C}$, one expects $\mathrm{E}$ to increase with $\mathrm{t}$, if at all. Surprisingly, our present data indicate an opposite trend. This work has been presented at two technical meetings. Because we are relying on very small variations of $E$, we plan to once again repeat our experiments for more reliable statistics before publishing important consequences of the observations so far.

Concerning the development of EXAFS at Brookhaven for determining local structure around $\mathrm{Na}$ and $\mathrm{Si}$, we are continuing collaboration with the group at AT\&T. The appropriate detection capability for low energy X-rays has not become operational yet. In the interim, however, we have successfully obtained EXAFS on both the network modifier and former cations in four $\mathrm{xRb}_{2} \mathrm{O}-(1-\mathrm{x}) \mathrm{GeO}_{2}(\mathrm{x}=0.01-0.20)$ glasses. Preliminary analysis indicates that Ge-O first shell bond length increases with $\mathrm{x}$, but for Rb-O it increases slightly from $x=0.01$ to 0.05 , remains unchanged to $x=0.10$ and then decreases for $x=0.20$. The disorder, both in $\mathrm{Rb}-\mathrm{O}$ and $\mathrm{Ge}-\mathrm{O}$ bonds, increases monotonically with $\mathrm{x}$. Bond lengths and coordination numbers around the two cations are yet to be analyzed.

The quartz experiments for determining the importance of amorphousness on ion transport is progressing well. We have obtained a low impurity crystal and determined its electrical conductivity in the c-direction $(\mathrm{E}-1.78 \mathrm{eV})$. Further, a test sample has been subjected to neutron irradiation at the Brookhaven reactor, and from the level of radioactivity we foresee no radiation hazard in working at Lehigh with the irradiated samples. 
Finally, we have successfully collaborated with Professor Nowick to investigate bulk electrical relaxation processes in silicate glasses (see the enclosed preprint). Our experiments show that the only bulk relaxation process is due to the "universal" power law dependence of conductivity; our results fail to show the bulk relaxation peak which is often quoted in the literature. We have also collaborated with Professor Kanert in investigating how the ion movement in heavy metal fluoride glasses compares with that in oxide glasses (see the enclosed preprint). There are indications of a new localized motion involving $F$ atoms. Ion movement in these glasses is particularly sensitive to the structural relaxation below $\mathrm{Tg}$ and hence they are particularly suitable for our program. 


\section{PUBLICATIONS:}

1. Ion Movement Relaxation in Inorganic Glass - Salient Features

J. Non-crystalline Solids 131, 961 (1991)

2. Measurement of Electrical Conductivity of Glasses

Trans. Am. Ceram. Soc. To be published.

3. On the Nature of Electrical Relaxation in Silicate Glasses

Proc. VII Int. Conf. Physics of Non-cryst. Solids. To be published.

4. Nuclear Spin Relaxation in Fluorozirconate Glass

Proc. VII Int. Conf. Physics of Non-cryst. Solids. To be published.

\section{PUBLICATIONS: ABSTRACTS ONLY}

1. Correlation between Structure and Ion Movement in Oxide Glasses

Diffusion and Defects in Materials - 1991, Moscow, USSR, July 1991

To be sent when available.

2. Effect of Glass Preparation Method on Ionic Conduction in Sodium-Borate Glass

93rd Annual Meeting of the American Ceramic Society

(Glass \& Optical Materials Division) - April 28 - May 2, 1991

Cincinnati, OHIO, U.S.A.

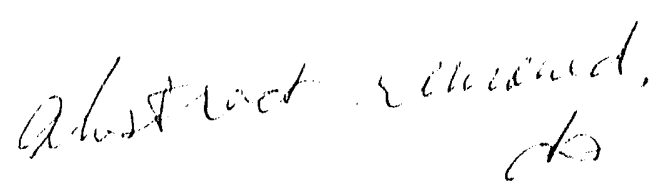


EFFECT OF GLASS PREPARATION METHOD ON IONIC CONDUCTION IN SODIUM-BORATE GLASS', W. C. Huang* and H. Jain, Dept. of Materials Sci. \& Eng., Lehigh University, Bethlehem, PA 18015-3195

It has been reported that the structure of a $\mathrm{B}_{2} \mathrm{O}_{3}$ glass depends on the temperature at which its melt is equilibrated before quenching [1]. In the present work we investigate the effect of structural differences arising from different preparation methods on ion transport. The ionic conduction and electrical relaxation of $0.3 \mathrm{Na}_{2} \mathrm{O}-0.7 \mathrm{~B}_{2} \mathrm{O}_{3}$ glass prepared by quenching the melt from different temperatures and at different cooling rates are studied. The relationship of the various preparation parameters to the structure and electrical properties will be discussed.

1. Kamitsos, E. I. \& Karakassides, M. A., Physics

Chem. Glasses 30(6), 235-236 (1989)

+. Work supported by U.S. Department of Energy (Grant

No. DE-FG02-90ER45419)

-- 93rd Annual Meeting of the American Ceramic Society (Glass \& Optical Materials Division), April 28-May 2,1991, Cincinnati, OHIO 

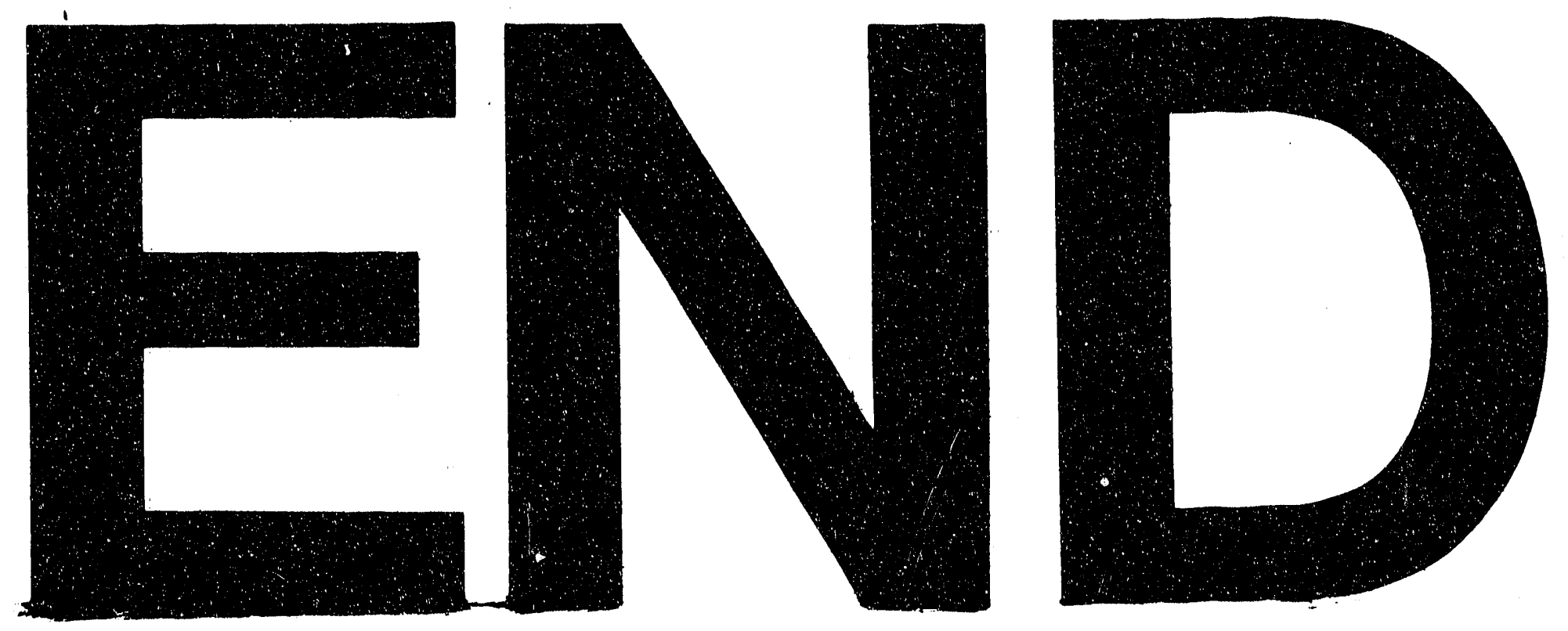

a.

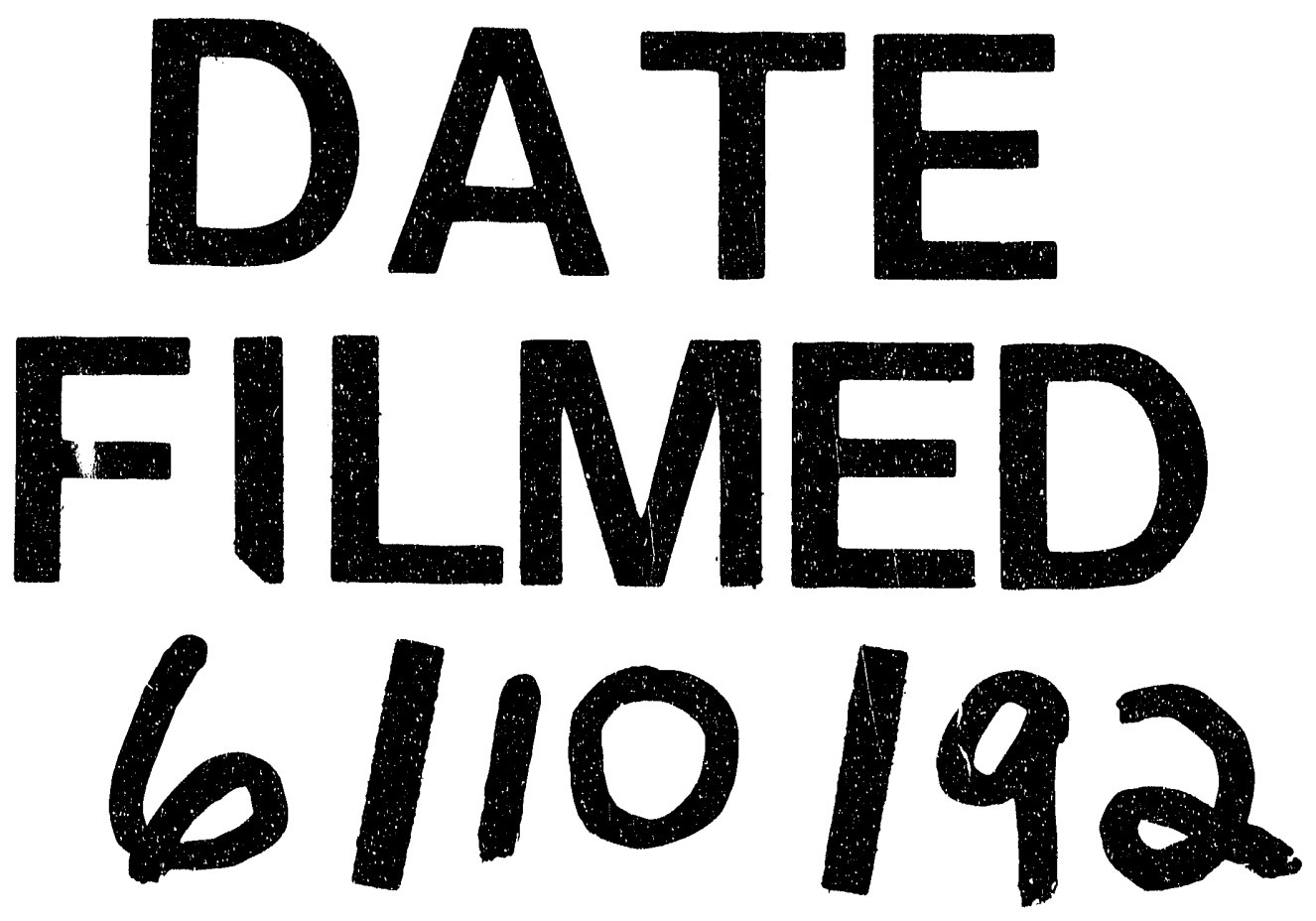


